https://doi.org/10.48009/1_iis_2014_20-27

Issues in Information Systems

Volume 15, Issue I, pp. 20-27, 2014

\title{
E-CHEATING: INCIDENCE AND TRENDS AMONG COLLEGE STUDENTS
}

\author{
Darwin L. King, St. Bonaventure University, dking@sbu.edu \\ Carl J. Case, St. Bonaventure University, ccase@sbu.edu
}

\begin{abstract}
There has been substantial research in the area of student cheating in traditional face-to-face classes but much less on cheating using technology often termed "e-cheating." With the increased offering of online courses to provide students with greater flexibility, concerns regarding academic integrity arise. How many opportunities exist for students to cheat when taking an online course? The authors have utilized a biannual survey to gather information on student cheating in both traditional and online courses. This paper summarizes the results of the authors' surveys for the past five years. Findings show that the most common type of cheating activity reported by students is the downloading of Internet papers and representing them as the student's own work. In addition, students report that they believe that other students cheat more on homework problems as compared to exams, term papers, and Internet projects. The most troubling finding for educators, however, is that e-cheating appears to be on the rise.
\end{abstract}

Keywords: E-Cheating, student cheating, ethics, technology, Internet, academic dishonesty

\section{INTRODUCTION}

A major concern for every faculty member is the potential opportunity for student academic dishonesty. The possibility for cheating by students on exams, homework, term papers, and other projects has always existed. With the introduction of technology in the classroom and the proliferation of online classes, the potential for what is termed "e-cheating" has increased tremendously. A 2009 study found that about $74 \%$ of students surveyed believed it was easier to cheat on an online class compared to the conventional class format [3]. The same study found that $32.1 \%$ of responding students admitted to cheating in a conventional class format while $32.7 \%$ admitted to cheating in an online course structure.

The authors' research utilized a survey that identified certain specific types of cheating. This included cheating on exams, homework, and term paper projects. This research, therefore, examines a number of different questions. Do students cheat more often on exams compared to homework or term papers? Is it easier to cheat on online vs. in class exams? What type of cheating do students believe that fellow students are committing? How many times do students report that he or she cheated on exams, homework, or term papers in a given semester?

The results of research of this type should be beneficial to institutions of higher learning to better understand the types of unethical behavior that could be committed by students in both traditional and online classes. If faculty understand that there exists multiple opportunities for students to cheat in a class, preventative internal controls can be developed to reduce the opportunity for this academic dishonesty to occur. Finally, more sophisticated controls may be necessary when online courses are being offered.

\section{PREVIOUS RESEARCH}

This study's authors conducted exploratory research studies in 2006 and 2007 to better understand student ethical behavior and to establish a baseline for future research. In particular, the study was undertaken to examine the state of online behavior from a longitudinal perspective.

The first exploratory study by the authors' was conducted in 2006 found that although $49 \%$ of students cheated at least once during the past 12 months in college, only six percent claimed using information technology (IT) to cheat on an exam and five percent indicated submitting a downloaded paper as their own [1]. Moreover, $49 \%$ stated that it was very or somewhat easy to cheat on an online exam. 


\section{Issues in Information Systems \\ Volume 15, Issue I, pp. 20-27, 2014}

A follow-up study was published in 2007. Results illustrate that although $15 \%$ of students indicated cheating on an exam, only four percent of students admitted using IT to cheat on an exam [2]. Fourteen percent stated that he/she let another student copy from their exam. Thirty-four percent of the students indicated permitting another student to copy their homework and only four percent admitted to downloading a research paper from the Internet and submitting it as his/her own work. Overall, forty-three percent of the students admitted to some type of unethical behavior including cheating on exams either with or without IT, letting others copy their homework or exams, downloading research papers as their own work, or cutting and pasting information from the Internet and not citing the source of the material.

Research conducted by Watson \& Sottile found that students believed that he or she would more likely cheat on an online course compared to a "live" class [4]. This research showed that about $42 \%$ of students believed that it was easier to cheat in an online class but felt that $61 \%$ of their classmates were more likely to cheat in an online format. The same researchers found that responding students admitted that they were more than four times more likely to cheat in an online class compared to the traditional in-class format.

Khan \& Balasubramanian found that increased online sources and readily available technology had a positive effect on students' attitude towards e-cheating [5]. These authors found that $37.5 \%$ of students surveyed admitted to traditional cheating (among friends during exams) while 78\% admitted to cheating using technology or e-cheating. In addition, students in this study admitted to using various devices to e-cheat including phones, programmable calculators, I-Pods, and memory sticks.

Several studies have investigated the reasons why students cheat in either a conventional face-to-face class or an online class. One study found a recurring theme was the student's desire "to get ahead" [6]. Other researchers have identified a number of other reasons including the desire to help others, procrastination, the need to pass the class, it doesn't matter if I cheat, and cheating is easy [7]. Instructors must be aware that there are a number of motivations causing students to cheat. These include an understandable desire to help friends in the class that are struggling. In the minds of many students this may appear to be a somewhat noble purpose.

Replogle has identified four reasons why college students cheat [13]. According to him the reasons include "everyone does it," "it's not my fault," "it's so easy to cheat," and finally "gotta keep up my GPA." Finally, Heibutzki identified five basic reasons that college students cheat. These include ambiguous attitudes of students, competitive pressures to succeed, institutional apathy on the part of faculty and administration, lack of understanding on the student's part as to what constitutes cheating, and student self-interest [14].

Two of the first researchers to use the term "e-cheating" were Styron \& Styron in 2010 [8]. E-cheating is now a fairly common term to describe student violations of academic integrity though the use of any technology oriented device. Within the last ten years many high technology devices have been introduced which could be used by unethical students to cheat in either a traditional or online class. Many authors feel that educators must employ more effective controls in an effort to minimize cheating in all forms [9]. These authors argue that a written academic dishonesty policy signed by all students is a good start, but educators must be proactive and devise more complex and innovative controls in an effort to minimize student cheating.

One of the more common methods of cheating in both face-to-face and online courses involves the downloading of completed papers from the Internet. Unethical students will then submit these documents and represent them as their own work. Researchers have published articles that list established Internet sites that contain completed papers on a wide variety of subjects. These websites, often termed "paper mills," include masterpapers.com, essaytown.com, writework.com, and schoolsucks.com [10]. The same author also listed sites that aid instructors in locating plagiarized materials including turnitin.com and safeassign.com. One of the authors' advisees submitted a plagiarized paper recently that was discovered by the student's instructor who used the turnitin site. 


\section{Issues in Information Systems \\ Volume 15, Issue I, pp. 20-27, 2014}

Research has also shown that academic cheating may increase the chances of dishonesty following graduation. A 2007 survey of Southern Illinois University students found that students viewed themselves more likely to break the rules in the workplace, cheat on spouses, and engage in other illegal activities [11]. A 2009 survey by the Josephson Institute of Ethics supports this premise and found that students who cheat in high school are three times more likely to inflate an insurance claim or lie to a customer. Educators must seriously consider the importance of proactive controls to minimize student's motivations to cheat. This includes a review of the school's academic dishonesty policy and a discussion of resulting penalties if the student is caught cheating. Previous research indicates that most faculty are concerned about e-cheating but most do not proactively implement controls to prevent it [12].

In summary, a significant amount of research has been conducted concerning cheating among college students. A well-known researcher on cheating is Donald McCabe. He and his associates have found that cheating is quite prevalent in U.S. colleges and universities and some forms of academic dishonest have increased rapidly in recent years [15]. These researchers feel that contextual factors such as the students' perceptions of peers' behavior may be more important than individual factors in the student's decision of whether or not to cheat. They stress the importance of an academic integrity policy or honor code for every institution of higher learning. Students must read and be familiar with these policies in order to understand what constitutes cheating. Finally, colleges and universities must adopt a discipline system with serious consequences to the student that contain material deterrent value. When cheating is discovered, the school must be willing to employ significant sanctions that send a message that cheating will not be tolerated on the campus.

\section{RESEARCH DESIGN}

This study employs a survey research design. The research was conducted at a private, northeastern U.S. university. A Student Ethical Behavior instrument was developed by the authors and administered to undergraduate students enrolled in a School of Business course. The courses included a variety of subjects such as Business Information Systems, Business Telecommunications, System Analysis and Design, Introduction to Financial Accounting, Introduction to Managerial Accounting, Management and Organization Behavior, Business Policy, and Women in Business. A convenience sample of class sections and faculty members was selected. The surveys were collected each semester during a five-consecutive year or 10-semester period (from Spring 2009 through Fall 2013).

The survey instrument was utilized to collect student demographic data such as gender and academic class. In addition, the survey examined student behavior with regard to cheating and ethical behavior. The survey requested that each student indicate the number of times during the past 12 months in college that he/she cheated in various ways (let others copy his/her exam, cheated on exam using IT, papers downloaded and submitted as his/her work, and so on). In addition, students were prompted to estimate the quantity of other students that cheat.

All surveys were anonymous and completed in an academic classroom. The response rate was 100 percent. Students were also informed that results would have no effect on their course grade.

\section{RESULTS}

A sample of 1,817 usable surveys was obtained. Table 1 indicates that $60 \%$ of the respondents were male and $40 \%$ were female. This $60 / 40$ ratio has remained fairly consistent over the identified five-year period.

Table 1. Gender Response Rate By Academic Year

\begin{tabular}{||c|r|r|r|r|r|r||}
\hline \hline & $\mathbf{2 0 0 9}$ & \multicolumn{1}{|c|}{$\mathbf{2 0 1 0}$} & $\mathbf{2 0 1 1}$ & $\mathbf{2 0 1 2}$ & \multicolumn{1}{c|}{$\mathbf{2 0 1 3}$} & \multicolumn{1}{c|}{ Total } \\
\hline \hline Male & $58 \%$ & $62 \%$ & $59 \%$ & $61 \%$ & $58 \%$ & $60 \%$ \\
\hline Female & $42 \%$ & $38 \%$ & $41 \%$ & $39 \%$ & $42 \%$ & $40 \%$ \\
\hline Count & 357 & 366 & 331 & 378 & 385 & 1817 \\
\hline
\end{tabular}




\section{Issues in Information Systems \\ Volume 15, Issue I, pp. 20-27, 2014}

The response rate by academic class is relatively equally distributed. Table 2 illustrates that $19 \%$ of respondents were freshmen, $37 \%$ were sophomores, $21 \%$ were juniors, and $23 \%$ were seniors.

Table 2. Academic Class Response Rate By Academic Year

\begin{tabular}{||l|r|r|r|r|r|r||}
\hline & $\mathbf{2 0 0 9}$ & $\mathbf{2 0 1 0}$ & $\mathbf{2 0 1 1}$ & $\mathbf{2 0 1 2}$ & $\mathbf{2 0 1 3}$ & \multicolumn{1}{c|}{ Total } \\
\hline \hline Freshmen & $28 \%$ & $17 \%$ & $18 \%$ & $21 \%$ & $12 \%$ & $19 \%$ \\
\hline Sophomore & $28 \%$ & $43 \%$ & $50 \%$ & $34 \%$ & $32 \%$ & $37 \%$ \\
\hline Junior & $17 \%$ & $24 \%$ & $18 \%$ & $18 \%$ & $26 \%$ & $21 \%$ \\
\hline Senior & $27 \%$ & $16 \%$ & $15 \%$ & $28 \%$ & $30 \%$ & $23 \%$ \\
\hline \hline
\end{tabular}

E-cheating activity was examined to determine the type of cheating activity committed (Table 3). Results for 2013, for example, illustrate that although $15 \%$ of students indicated cheating on an exam, only $10 \%$ of students admitted using IT to cheat on an exam. Sixteen percent stated that he/she let another student copy from their exam. Thirtyone percent of the students indicated permitting another student to copy their homework. Only ten percent admitted to downloading a research paper from the Internet and submitting it as his/her own work. The most common type of cheating committed every year of the study involved copying homework. For many students, this practice is not considered cheating or unethical behavior. Approximately half (44\%) of the students committed at least one of the unethical activities listed in Table 3. With new IT devices flooding the market in recent years, students demonstrated a substantial increase in their use of these items from $2009(3 \%)$ to $2013(10 \%)$ as a way to cheat on exams. Overall, unethical activity increased from 34\% of students in 2009 to $44 \%$ of students in 2013.

Table 3. Type of Cheating Activity (\% of Respondents)

\begin{tabular}{||l|r|r|r|r|r||}
\hline \multicolumn{1}{|c|}{ Activity } & $\mathbf{2 0 0 9}$ & $\mathbf{2 0 1 0}$ & $\mathbf{2 0 1 1}$ & $\mathbf{2 0 1 2}$ & $\mathbf{2 0 1 3}$ \\
\hline \hline Cheated on an exam & $7 \%$ & $16 \%$ & $16 \%$ & $13 \%$ & $15 \%$ \\
\hline Cheated on exams using IT & $3 \%$ & $7 \%$ & $4 \%$ & $8 \%$ & $10 \%$ \\
\hline Let others copy from my exam & $7 \%$ & $10 \%$ & $11 \%$ & $8 \%$ & $16 \%$ \\
\hline Let others copy my homework & $27 \%$ & $31 \%$ & $30 \%$ & $30 \%$ & $31 \%$ \\
\hline Downloaded Internet papers as his/her own work & $3 \%$ & $7 \%$ & $4 \%$ & $8 \%$ & $10 \%$ \\
\hline \hline At least once unethical activity from above (unduplicated) & $34 \%$ & $41 \%$ & $39 \%$ & $41 \%$ & $44 \%$ \\
\hline
\end{tabular}

Table 4 presents e-cheating activity by incidence. The most predominant type of cheating reported by the students is the downloading of completed papers from the Internet that are submitted as the students own work. Given the number of 'paper mills' on the Internet today, this is a very simple task for students to accomplish. Students reporting that they committed this act on average of 7.3 times per semester in 2009 but 13.9 times per semester in 2013. This likely represented the vast majority of papers submitted by these students. Cheating on an exam, cheating on exams using IT, letting others copy from his/her exam, and letting others copy from his/her homework occurred much less frequently. For each of these four activities, incidence was fairly consistent across the five-year study period.

Table 4. Type of Cheating Activity (Average Number of Times Per Semester)

\begin{tabular}{||l|r|r|r|r|r||}
\hline \multicolumn{1}{|c|}{ Activity } & $\mathbf{2 0 0 9}$ & \multicolumn{1}{|c|}{$\mathbf{2 0 1 0}$} & \multicolumn{1}{c|}{$\mathbf{2 0 1 1}$} & \multicolumn{1}{|c|}{$\mathbf{2 0 1 2}$} & \multicolumn{1}{|c|}{$\mathbf{2 0 1 3}$} \\
\hline \hline Cheated on an exam & 3.7 & 4.1 & 3.1 & 3.0 & 2.9 \\
\hline Cheated on exams using IT & 4.6 & 6.5 & 2.7 & 2.1 & 3.7 \\
\hline Let others copy from my exam & 3.1 & 2.9 & 3.0 & 3.1 & 2.6 \\
\hline Let others copy my homework & 4.5 & 3.9 & 5.1 & 4.6 & 4.4 \\
\hline Downloaded Internet papers as his/her own work & 7.3 & 14.7 & 6.1 & 13.9 & 13.4 \\
\hline
\end{tabular}




\section{Issues in Information Systems \\ Volume 15, Issue I, pp. 20-27, 2014}

The authors' survey also included a question on how easy it would be to cheat on online exams. Table 5 demonstrates that $29 \%$ of the students in 2013 felt that it was very easy to cheat on an online exam, $45 \%$ thought it would be somewhat easy, $20 \%$ said it would be difficult and $7 \%$ stated it would be very difficult. Overall, $74 \%$ of students in 2013 indicated it would be very or somewhat easy to cheat on an online exam. This compares to only $63 \%$ of the students reporting similar views in $2009,62 \%$ in $2010,67 \%$ in 2011 , and $68 \%$ in 2012 . Based upon these perceptions, it is apparent that a majority of students see the potential opportunity to easily cheat on online exams.

Table 5. Ease of Cheating on Online Course Exams (Students had taken an online course)

\begin{tabular}{||l|r|r|r|r|r||}
\hline \multicolumn{1}{|c|}{ Ease of Cheating } & $\mathbf{2 0 0 9}$ & $\mathbf{2 0 1 0}$ & $\mathbf{2 0 1 1}$ & $\mathbf{2 0 1 2}$ & $\mathbf{2 0 1 3}$ \\
\hline \hline Very easy to cheat & $23 \%$ & $23 \%$ & $28 \%$ & $23 \%$ & $29 \%$ \\
\hline Somewhat easy to cheat & $40 \%$ & $39 \%$ & $39 \%$ & $45 \%$ & $45 \%$ \\
\hline Difficult to cheat & $28 \%$ & $31 \%$ & $27 \%$ & $22 \%$ & $20 \%$ \\
\hline Very difficult to cheat & $8 \%$ & $7 \%$ & $6 \%$ & $10 \%$ & $7 \%$ \\
\hline
\end{tabular}

The students who had taken an online course were asked if they cheated on these exams and how many times this activity took place. Table 6 shows that for 2013 about $29 \%$ of the students admitted to cheating on online exams. This was a much higher percentage than was reported in the previous four years. The increase from $17 \%$ in 2012 to $29 \%$ in 2013 is likely, at least partially, a result of the increased number of online classes offered by the study university in recent years. The average number of online exam cheating incidents per student was fairly consistent at about 3.5 times per year. The disturbing fact is that in 2013 about one-third of students taking an online course reported that he or she cheated on the exams. This is nearly a $50 \%$ increase from 2009 . This suggests that faculty teaching online course must plan a more proactive prevention approach in order to minimize cheating on the online exams.

Table 6. Online Exam Cheating

\begin{tabular}{||l|r|r|r|r|r||}
\hline \multicolumn{1}{|c|}{ Factor } & $\mathbf{2 0 0 9}$ & $\mathbf{2 0 1 0}$ & $\mathbf{2 0 1 1}$ & $\mathbf{2 0 1 2}$ & $\mathbf{2 0 1 3}$ \\
\hline \hline \% of students that cheat on online exams & $20 \%$ & $17 \%$ & $15 \%$ & $17 \%$ & $29 \%$ \\
\hline $\begin{array}{l}\text { Average number of online exam cheating } \\
\text { incidents per student }\end{array}$ & 3.0 & 2.9 & 3.5 & 3.7 & 3.3 \\
\hline
\end{tabular}

Finally, the students were prompted to estimate the percentage of their fellow students that cheat on exams, homework, Internet projects, and research papers. Respondents indicated that the most common dishonest activity was cheating on homework (Table 7). Anecdotal conversations with students often gather the response that providing friends and classmates with homework solutions is really not a form of cheating but instead a way to help and assist struggling colleagues. The less common forms of unethical behavior, in decreasing percentage of students, were cheating on Internet projects, exams, and term papers. In 2013, for example, students estimated that $44 \%$ of classmates cheat on homework, $36 \%$ cheat on Internet projects, $29 \%$ cheat on exams, and $25 \%$ cheat on term papers. When comparing academic years, student estimates are fairly consistent per activity for each year.

Table 7. Student Estimates of Cheating by Other Students

\begin{tabular}{|l|r|r|r|r|r||}
\hline \hline \multicolumn{1}{|c|}{ Activity } & $\mathbf{2 0 0 9}$ & $\mathbf{2 0 1 0}$ & $\mathbf{2 0 1 1}$ & $\mathbf{2 0 1 2}$ & $\mathbf{2 0 1 3}$ \\
\hline \hline Homework & $42 \%$ & $42 \%$ & $45 \%$ & $43 \%$ & $44 \%$ \\
\hline Exams & $25 \%$ & $24 \%$ & $28 \%$ & $27 \%$ & $29 \%$ \\
\hline Term Papers & $22 \%$ & $21 \%$ & $24 \%$ & $25 \%$ & $25 \%$ \\
\hline Internet Projects & $32 \%$ & $33 \%$ & $36 \%$ & $36 \%$ & $36 \%$ \\
\hline
\end{tabular}




\section{Issues in Information Systems \\ Volume 15, Issue I, pp. 20-27, 2014}

\section{CONCLUSIONS, IMPLICATIONS, AND LIMITATIONS}

Results indicate that students are cheating in various ways regardless of the course delivery mode. In 2013, for instance, $15 \%$ of students admitted cheating on exams, $10 \%$ said they used IT to cheat on the exams, $15 \%$ let other students copy from their exam, $31 \%$ let classmates copy his or her homework, and $10 \%$ reported that they downloaded Internet papers and submitted them as their own work. The latter act of academic dishonesty increased from only $3 \%$ in 2009 to $10 \%$ in 2013 . The type of cheating that was most common, letting other students copy homework solution, remained fairly constant at about $30 \%$ per year.

Moreover, $15 \%$ of the students admitted to cheating on an exam in 2013. That reporting group of students committed this act approximately 2.9 times each semester. Likewise, the $10 \%$ of students who admitted to downloading completed papers from the Internet in 2013 committed this act approximately 13.4 times during the semester. In many cases, this volume of plagiarized likely represented the vast majority of required papers for the semester for that student. Of the $10 \%$ of students who reported that they used IT to cheat on exams, the average number of these cheating events was 3.7 in 2013.

In terms of the student's feeling on how easy it would be to cheat on online exams, in 2013, $74 \%$ of students felt that it was either very easy or somewhat easy to cheat on an online exam. Only $7 \%$ reported that it would be difficult to cheat on said exams. This percentage increased substantially since 2009 when only $63 \%$ of students felt it was easy or somewhat easy to cheat on such exams. Similarly, roughly $29 \%$ of students taking an online course in 2013 cheated on exams. On average, they committed this action 3.3 times during the course. With the increased number of online classes being offered, faculty must be aware of the increased potential for cheating. When exams are taken from the student's home, any number of unethical practices could be employed. These range from using text and notes when the exam is closed book to having a friend or classmate take the exam for the registered student.

Finally, results indicate that students believe their fellow classmates are fairly unethical and often resort to cheating. In 2013 , surveyed students felt that $44 \%$ of their colleagues cheated on homework, $29 \%$ cheated on exams, $25 \%$ cheated on term papers, and $36 \%$ cheated on Internet projects. These are startling figures given the author's study was conducted at a private religious-based university.

Overall, the study illustrates that the percentage of students who committed at least one type of identified cheating activity rose from $34 \%$ of students in 2009 to $44 \%$ of students in 2013 . Cheating using IT rose dramatically from $3 \%$ of the students reporting that they committed this action in 2009 to $10 \%$ of students reporting the same activity in 2013. Likewise, downloading Internet papers and representing them as the student's own work increased from $3 \%$ in 2009 to $10 \%$ in 2013. A three-fold increase in both of these methods of academic dishonesty is something that faculty must consider especially when teaching an online course. Also, in 2013, 74\% of students indicated that it is either very easy or somewhat easy to cheat on online exams. This compares to only $63 \%$ with these same views in 2009.

\section{Implications}

There are three important implications as a result of these findings:

1. One implication is that the percentage of students committing academic cheating activity is on the rise. During the 2009-2013 study period, the percentage of students admitting to any type of cheating increased by $29 \%$. Faculty must therefore design classes with well-designed controls that strive to minimize the amount of dishonest activity. This conclusion is consistent with much of the recent research on academic dishonesty. In addition, the instructor must be willing and able to enforce the controls. It is certainly difficult to severely penalize students that the faculty has grown to know and respect. Many university and college codes of ethics include discipline actions that include either failing the assignment where the cheating took place, failing the entire course, and even expulsion from the institution. Studies have shown 


\section{Issues in Information Systems \\ Volume 15, Issue I, pp. 20-27, 2014}

that many instances of cheated are not adjudicated. Faculty must be willing to carry out the penalties that are discussed in their syllabi or contained in the institution's code of conduct or honor code.

2. A second implication is that the most common type of cheating by volume is the downloading of papers from the Internet and representing those documents as the student's own work. The author's study in 2013 found that on average 13 papers were downloaded in a given semester per offending student. It appears that students who admit to downloading completed papers must follow this practice in every class they took in order to generate a semester volume of this magnitude. Therefore, faculty must be prepared to use Internet sites such as turnitin.com and safeassign.com to identify papers that have been plagiarized.

3. A third implication is that students overwhelming believe that it is easy to cheat on an online exam. The author's survey in 2013 revealed that $74 \%$ of students believe it is either very easy or somewhat easy to cheat on an online exam. Since online courses are becoming more common each year, faculty must be aware of the potential for student cheating on the exams. Since it is impossible to enforce a closed book policy when students are taking the exams from their homes, the logical control is an enforced time limit that restricts students from researching each question in the text or class notes. Ensuring that it is the registered student who is actually taking the exam remains a problem. The possibility of another "coach" in the room to help in answering questions and problems also is a concern. A potential solution is requiring exams for online classes to be taken in a proctored physical location. This requirement, however, may create logistical challenges and decrease the time-shifting flexibility associated with online courses.

The limitations of this study are primarily a function of the sample and type of research. Even though responses were relatively equally distributed among academic class, a more equal gender distribution of respondents and use of additional universities would increase the robustness of results. Another limitation relates to the self-reported nature of the survey.

\section{REFERENCES}

1. Case, C. J. \& D. L. King (2007). The Decision to E-Cheat. Business Research Yearbook, Global Business Perspectives. Volume XIV, 143-148.

2. King, D. L. \& C. J. Case (2007). E-Cheating: Are Students Misusing IT? Issues in Information Systems. Volume XIII(1), 71-75.

3. King, C., Guyette, R., and Piotrowski, C. (2009). Online exams and cheating: An empirical analysis of business student's views. The Journal of Educators Online, 6(1), 1-11.

4. Watson, G. \& Sottile, J. (2010). Cheating in the Digital Age: Do Students Cheat More in Online Courses? Online Journal of Distance Learning Administration, Volume XIII, Number 1, Spring 2010. University of West Georgia, Distance Education Center.

5. Khan, Z. \& Balasubramanian, S. (2012). Students go click, flick and cheat...e-cheating, technologies, and more. Journal of Academic and Business Ethics, 1-26.

6. Simkin, M.G., \& McLeod (2009). Why Do College Students Cheat? Journal of Business Ethics, Vol. 94, 441453.

7. Owunwanne, D., Rustagi, N. \& Dada, R. (2010). Students Perceptions of Cheating and Plagiarism in Higher Institutions. Journal of College Teaching \& Learning, Vol. 7, No. 11, 59-67.

8. Styron, J. \& Styron, R.A. (2010). Student Cheating and Alternative Web-based Assessment. Journal of College Teaching \& Learning, Vol. 7, No. 5, 37-42.

9. Molten, Jr. J., Fitterer, A., Brazier, E., Leonard, J., and Brown, A. (2013). Examining Online College Cyber Cheating Methods and Prevention Measures. The Electronic Journal of e-Learning, Vol. 11, Issue 2, 139-146.

10. McMurtry, K. (2001). E-cheating: Combating a $21^{\text {st }}$ Century Challenge. T.H.E. Journal, http://thejournal.com.

11. Novotney, A. (2011). Beat the Cheat, American Psychological Association, Vol. 42, No. 6, 54.

12. Rogers, C. (2006). Faculty Perceptions About E-Cheating During Online Testing, Consortium for Computing Sciences in Colleges, 2006, 206-212.

13. Replogle, D. (2013). Top 4 Reasons College Students Cheat. The Real College Guide, downloaded from 


\section{Issues in Information Systems}

Volume 15, Issue I, pp. 20-27, 2014

http://www.higheredmorning.com on 11/23/13.

14. Heibutzki, R. (2013). Statistics on Why College Students Decide to Cheat. downloaded from http://everydaylife.globalpost.com on 12/4/13.

15. McCabe, D., Trevino, L. \& Butterfield, K. (2001). Cheating in Academic Institutions: A Decade of Research. Ethics \& Behavior, 11(3), 219-232. 